\title{
Delayed Neurobehavioral Development in Children Born to Pregnant Women with Mild Hypothyroxinemia During the First Month of Gestation: The Importance of Early lodine Supplementation
}

\author{
Pere Berbel, ${ }^{1}$ José Luis Mestre,${ }^{2, \star}$ Asunción Santamaría, ${ }^{1,3}$ Inmaculada Palazón, ${ }^{4}$ Ascensión Franco, ${ }^{1}$ \\ Marisa Graells, ${ }^{5, \dagger}$ Antonio González-Torga, ${ }^{6}$ and Gabriella Morreale de Escobar ${ }^{7}$
}

Background: Maternal hypothyroxinemia, due to gestational iodine deficiency, causes neurological dysfunctions in the progeny. Our aim was to determine the effects of delayed iodine supplementation ( $200 \mu \mathrm{g}$ KI per day) to mildly hypothyroxinemic pregnant women at the beginning of gestation (i.e., having circulating free thyroxine $\left[\mathrm{FT}_{4}\right]$ within the 0th-10th percentile interval and normal thyrotropin [TSH]) on the neurobehavioral development of their children.

Methods: Using the Brunet-Lézine scale, we evaluated the neurocognitive performance at 18 months of age in three groups of children. Group 1 included children of women with $\mathrm{FT}_{4}$ above the 20th percentile at 4-6 gestational weeks and at full-term. Group 2 included children of mildly hypothyroxinemic women diagnosed during the first 12-14 gestational weeks and with $\mathrm{FT}_{4}$ above the 20th percentile at full-term. Group 3 included children born to mildly hypothyroxinemic women at full-term, without iodine supplementation during gestation. Women of all groups were iodine supplemented from the day of enrollment until the end of lactation.

Results: Before iodine supplementation, $33.0 \%$ of the women (114 out of 345) were hypothyroxinemic, with $\mathrm{FT}_{4}$ below normal in 28 of them $(8.1 \%)$. None were found to be hypothyroxinemic at full-term after supplementation. The mean $( \pm \mathrm{SD})$ developmental quotient of children was $101.8 \pm 9.7$ in group $1(n=13)$ vs. $87.5 \pm 8.9$ in group $3(n=19$; $p<0.001)$ and $92.2 \pm 5.4$ in group $2(n=12 ; p<0.05)$. The difference between groups 2 and 3 was not statistically significant. Delayed neurobehavioral performance was observed in $36.8 \%$ and $25.0 \%$ of children in groups 3 and 2 , respectively, compared with no children in group 1 . Differences $(p<0.001)$ were found on gross and fine motor coordination and socialization quotients. No statistically significant differences were found on language quotients. Conclusions: A delay of 6-10 weeks in iodine supplementation of hypothyroxinemic mothers at the beginning of gestation increases the risk of neurodevelopmental delay in the progeny. Public health programs should address the growing problem of iodine deficiency among women of gestational age in developing and industrialized nations.

\section{Introduction}

I ODINE DEFICIENCY IS one of the most frequent causes worldwide of preventable mental retardation in children. A wide spectrum of iodine deficiency disorders has been described during gestation, ranging from abortion to congenital anomalies, deafness, neurological cretinism, neurocognitive delay, and mental retardation, as well as attention deficit hyperactivity disorder, among others $(1,2)$. In children, the severity of the neurodevelopmental damage caused by iodine deficiency during gestation depends on the developmental period affected by this condition and on its severity.

\footnotetext{
*Present address: Pediatrics, Hospital Universitario de Sant Joan, Sant Joan d'Alacant, Alicante, Spain.

†resent address: Biochemistry Laboratory, Hospital General Universitario de Alicante, Alicante, Spain.

${ }^{1}$ Instituto de Neurociencias de Alicante, Universidad Miguel Hernández and Consejo Superior de Investigaciones Científicas (CSIC), Alicante, Spain.

${ }^{2}$ Obstetrics, Gynecology and Pediatrics, Hospital Marina Baixa, La Vila Joiosa, Alicante, Spain.

${ }^{3}$ Center of Primary Health Care "Foietes", Benidorm, Alicante, Spain.

${ }^{4}$ Pediatrics, Clinical Child Psychology, Hospital General Universitario, Alicante, Spain.

${ }^{5}$ Biochemistry Laboratory, Hospital Marina Baixa, La Vila Joiosa, Alicante, Spain.

${ }^{6}$ Preventive Medicine, Hospital General Universitario, Alicante, Spain.

${ }^{7}$ Instituto de Investigaciones Biomédicas "Alberto Sols", CSIC and Universidad Autónoma de Madrid, Madrid, and Centro de Investigación Biomédica en Red de Enfermedades Raras (CIBERER), ISCIII, Madrid, Spain.
} 
Iodine is an essential component of the thyroid hormones, thyroxine $\left(\mathrm{T}_{4}\right)$ and triiodothyronine $\left(\mathrm{T}_{3}\right)$. Iodine intake is especially crucial during gestation and lactation, since during these developmental periods the mother is the only source of iodine for the fetus and the neonate. Most critical for brain development is the fact that $\mathrm{T}_{3}$ (the active hormone interacting with nuclear thyroid receptors) is produced by the fetus from maternal $T_{4}$ and this is the only source of $T_{4}$ for the fetus during the first trimester of pregnancy (3-7). During this critical period fundamental processes occur in the development of the fetal central nervous system. In particular, the cerebral vesicles, from which the cerebral cortex develops, become recognizable in the developing central nervous system by embryonic day 35 and the neocortical development begins by embryonic day 46 (8). The concentration of $T_{3} n u-$ clear receptors is low at the beginning of neocortical development but it progressively increases 10 -fold by the 16th week of gestation (9), in parallel to neuroblast proliferation and neuronal migration (8). This makes the human brain especially vulnerable during development to deficiencies of iodine and thyroid hormones, not only because of their action through nuclear receptors $(9,10)$, but also for their possible nongenomic effects that might take place even earlier. For instance, recent studies have shown that thyroid hormone can link integrin $\alpha \mathrm{V} \beta 3$ receptor, which may induce angiogenesis by activation of the mitogen-activated protein kinase signal transduction cascade (11).

Epidemiological studies have shown neurological alterations in children born to mildly to moderately hypothyroxinemic mothers: at least $50 \%$ of the offspring of women with free $\mathrm{T}_{4}\left(\mathrm{FT}_{4}\right)$ below the normal 10th percentile had delayed neurobehavioral development (12-15). An important prospective study disclosed that the children of mothers suffering mild to moderate iodine deficiency during the first trimester had an intelligence quotient (IQ) that was 10-15 points below the normal mean values and that 11 of 16 children of the moderately iodine-deficient area $(68.7 \%)$ presented attention deficit hyperactivity disorder (16). In contrast, none of the children from mothers who were not hypothyroxinemic during the first trimester had this syndrome.

Experimental studies performed in rodents are consistent with the results from epidemiological studies: the tangential and radial migrations of cortical neurons in the pups of hypothyroxinemic dams are abnormal resulting in ectopic neurons in different cortical layers, especially in the subcortical white matter and in the alveus of the hippocampus. These ectopias were found even when the maternal hypothyroxinemia was mild and transient at the beginning of corticogenesis (17-20). Whether or not such a critical period also exists in humans at the beginning of corticogenesis is unknown.

We here explore if mild and transient hypothyroxinemia in pregnant women during the first trimester of gestation in a mildly iodine-deficient region, when the bulk of fetal neocortical proliferation has already occurred, may affect the neurobehavioral development of their children.

\section{Subjects and Methods \\ Subjects}

This study was performed in the area of Marina Baixa (Alicante, Spain). Three groups of pregnant women were included (Table 1) and neurocognitive evaluation of strictly selected children (Table 2 ) was performed at 18 months of age. These women were enrolled during the first 2-3 months after the beginning of this study. Women of groups 1 and 2 were enrolled at their first pregnancy visit (by a midwife or gynecologist); women of group 3 were enrolled at full-term. All women were supplemented orally with iodine $(200 \mu \mathrm{g}$ KI per day) from the day of enrollment to the end of lactation. The

Table 1. Number of Mothers with Different Serum Concentrations of Free Thyroxine and Thyrotropin at Different Gestational Weeks

\begin{tabular}{|c|c|c|c|c|c|}
\hline & \multicolumn{2}{|c|}{$\begin{array}{l}\text { Group } 1 \text { KI from } \\
4-6 \text { GW }(\mathrm{n}=92)\end{array}$} & \multicolumn{2}{|c|}{$\begin{array}{c}\text { Group } 2 \text { KI from } \\
12-14 \text { GW }(\mathrm{n}=102)\end{array}$} & \multirow{2}{*}{$\begin{array}{l}\begin{array}{l}\text { Group } 3 \text { KI after } \\
\text { delivery }(\mathrm{n}=151)\end{array} \\
\text { At term }\end{array}$} \\
\hline & At 4-6 GW & At term ${ }^{\mathrm{a}}$ & At $12-14 \mathrm{GW}$ & At term ${ }^{\mathrm{b}}$ & \\
\hline No hypothyroxinemia & $64(69.6 \%)$ & $45(100.0 \%)$ & $73(71.6 \%)$ & $28(100.0 \%)$ & $94(62.3 \%)$ \\
\hline $\mathrm{FT}_{4}$ (20th-100th); normal TSH & $46(50.0 \%)$ & $43(95.6 \%)$ & $48(47.1 \%)$ & $21+3^{c}(85.7 \%)$ & $59(39.1 \%)$ \\
\hline $\mathrm{FT}_{4}$ (10th-20th); normal TSH & $17(18.5 \%)$ & $2(4.4 \%)$ & $24(23.5 \%)$ & $4(14.3 \%)$ & $32(21.2 \%)$ \\
\hline $\mathrm{FT}_{4}$ (20th-100th); TSH >4.80 & $1(1.1 \%)$ & & $1(1.0 \%)$ & & $3(2.0 \%)$ \\
\hline Hypothyroxinemia & $28(30.4 \%)$ & & $29(28.4 \%)$ & & $57(37.7 \%)$ \\
\hline $\mathrm{FT}_{4}$ (0th-10th); normal TSH & $22(23.9 \%)$ & & $21(20.6 \%)$ & & $40(26.5 \%)$ \\
\hline $\mathrm{FT}_{4}$ (0th-10th); $\mathrm{TSH}<0.38$ & & & & & $2(1.3 \%)$ \\
\hline $\mathrm{FT}_{4}<0.71 ;$ normal TSH & $6(6.5 \%)$ & & $7(6.9 \%)$ & & $15(9.9 \%)$ \\
\hline $\mathrm{FT}_{4}<0.71 ; \mathrm{TSH}>4.80$ & & & $1(1.0 \%)$ & & \\
\hline
\end{tabular}

The $\mathrm{FT}_{4}$ concentration limits for the 0th-10th percentile interval are 0.71 and $0.82 \mathrm{ng} / \mathrm{dL}$; for the 10th-20th percentile interval, 0.83 and $0.91 \mathrm{ng} / \mathrm{dL}$; and for the 20th-100th percentile interval, 0.92 and $1.85 \mathrm{ng} / \mathrm{dL}$. The normal range for $\mathrm{FT}_{4}$ is $0.71-1.85 \mathrm{ng} / \mathrm{dL}$ and for TSH is $0.38-$ $4.80 \mu \mathrm{IU} / \mathrm{mL}$. The groups from which the neurocognitive evaluated children were derived are indicated in bold.

${ }^{a}$ Only women with $\mathrm{FT}_{4}$ within the 20th-100th percentile interval at 4-6 GW and with normal TSH are included in this column, one woman that had a spontaneous abortion being excluded.

${ }^{\mathrm{b}}$ Only hypothyroxinemic women at 12-14 GW with normal TSH are included in this column, one woman with TSH above the normal range being excluded.

${ }^{c}$ Including three out of seven women with $\mathrm{FT}_{4}$ below the normal range at $12-14 \mathrm{GW}$; the children of these women were excluded from neurocognitive evaluation.

$\mathrm{GW}$, gestational week; $\mathrm{FT}_{4}$, free thyroxine; $\mathrm{TSH}$, thyrotropin. 
TABle 2. EPidemiological AND Socio-Cultural EXCLUSION CRITERIA

\begin{tabular}{|c|c|c|c|}
\hline Cause for exclusion & $\begin{array}{l}\text { Group } 1 \\
(\mathrm{n}=43)^{\mathrm{a}}\end{array}$ & $\begin{array}{l}\text { Group } 2 \\
(\mathrm{n}=21)\end{array}$ & $\begin{array}{l}\text { Group } 3 \\
(\mathrm{n}=40)\end{array}$ \\
\hline Total excluded ${ }^{\mathrm{b}}$ & 30 & 9 & 22 \\
\hline \multicolumn{4}{|l|}{ Delivery } \\
\hline Death at birth & 1 & 0 & 1 \\
\hline Caesarean section & 8 & 4 & 8 \\
\hline Neonatal characteristics $^{c}$ & 3 & 1 & 4 \\
\hline $\begin{array}{l}\text { APGAR }<6 \text { (at } 5 \text { min } \\
\text { after birth) }\end{array}$ & 2 & 1 & 1 \\
\hline Severe malformation & 1 & 0 & 0 \\
\hline Severe disease & 2 & 1 & 2 \\
\hline Early postnatal death & 1 & 1 & 2 \\
\hline Abstinence syndrome & 2 & 0 & 1 \\
\hline \multicolumn{4}{|l|}{ Lactation and 1st year of life } \\
\hline Lactation $<6$ months & 3 & 1 & 1 \\
\hline $\begin{array}{l}\text { Tonic neck reflex } \\
\text { at } 8 \text { th month }\end{array}$ & 0 & 0 & 1 \\
\hline Hypoacusia & 2 & 1 & 1 \\
\hline Severe malformation & 1 & 1 & 0 \\
\hline Blindness & 1 & 0 & 0 \\
\hline Severe disease & 3 & 0 & 2 \\
\hline Death & 0 & 0 & 1 \\
\hline Poor parental care & 0 & 0 & 1 \\
\hline \multicolumn{4}{|l|}{ Maternal } \\
\hline Weight increase $\mathrm{d}^{\mathrm{d}}$ & 10 & 2 & 3 \\
\hline Toxic habits (drugs): & 8 & 8 & 14 \\
\hline Alcohol $^{\mathrm{e}}$ & 5 & 5 & 9 \\
\hline Tobacco $^{\text {f }}$ & 6 & 4 & 9 \\
\hline Others & 6 & 3 & 7 \\
\hline \multicolumn{4}{|l|}{ Sociocultural factors } \\
\hline Rural & 5 & 1 & 4 \\
\hline Single parent family & 3 & 0 & 1 \\
\hline $\begin{array}{l}\text { School education } \\
(<14 \mathrm{y})^{\mathrm{g}}\end{array}$ & 1 & 1 & 3 \\
\hline Unemployment ${ }^{\mathrm{g}}$ & 0 & 0 & 1 \\
\hline $\begin{array}{l}\text { Without known } \\
\text { profession }^{\mathrm{g}}\end{array}$ & 6 & 2 & 5 \\
\hline
\end{tabular}

${ }^{a}$ The total number $(n)$ of women per group who passed the inclusion criteria shown in Table 1.

${ }^{\mathrm{b}}$ Including the cases that did not return for evaluation of the children (10 cases in group 1, two cases in group 2, and three cases in group 3).

${ }^{\text {c} C h i l d r e n ~ w i t h ~ w e i g h t ~ o u t s i d e ~ t h e ~} 2500-4000 \mathrm{~g}$ range, height outside the $47-53 \mathrm{~cm}$ range, and cephalic perimeter outside the $33-$ $37 \mathrm{~cm}$ range.

${ }^{\mathrm{d}}$ Women with weight increase during gestation outside the 6$15 \mathrm{~kg}$ range.

eDrinking other than $0 \mathrm{~mL}$ throughout.

${ }^{\mathrm{f}} \mathrm{S}$ moking more than 10 cigarettes per week throughout.

${ }^{\mathrm{g}}$ Both parents.

procedures followed were in accordance with the ethical standards of the European Union on human experimentation and approved by the Ethics Committee of the University Miguel Hernández.

Group 1 (Table 1) consisted of 92 women who were enrolled at $4-6$ gestational weeks. They were then supplemented with iodine ( $200 \mu \mathrm{g}$ KI per day) until full-term and throughout lactation, with the exception of one case with thyrotropin (TSH) $>4.8 \mu \mathrm{IU} / \mathrm{mL}$, who was referred to an endocrinologist and excluded from the group. Neurocognitively evaluated children (13 of 45 children) were born to women with normal
TSH and $\mathrm{FT}_{4}$ above the 20th percentile at the beginning of gestation and at full-term, and not affected by the exclusion criteria (32 of 45 children; Table 3).

Group 2 (Table 1) consisted of 102 women enrolled at the beginning of the second trimester (12-14 gestational weeks). They were then supplemented with iodine (200 $\mu \mathrm{g}$ KI per day) until full-term and throughout lactation, with the exception of two cases with $\mathrm{TSH}>4.8 \mu \mathrm{IU} / \mathrm{mL}$, who were referred to an endocrinologist and excluded from the group. Neurocognitive evaluated children (12 of 21 children) were born to mildly hypothyroxinemic women with normal TSH and with $\mathrm{FT}_{4}$ within the 0th-10th percentile interval during the first trimester, and $\mathrm{FT}_{4}$ above the 20th percentile at full-term, and not affected by the exclusion criteria (9 of 21 children; Table 3).

Group 3 (Table 1) consisted of 151 women enrolled at fullterm (37-40 gestational weeks); they were then supplemented with iodine (200 $\mu \mathrm{g}$ KI per day) throughout lactation, with the exception of five cases with abnormal TSH (three women with $\mathrm{TSH}>4.80 \mu \mathrm{IU} / \mathrm{mL}$, and two with $\mathrm{TSH}<0.38 \mu \mathrm{IU} / \mathrm{mL}$ ), who were referred to an endocrinologist and excluded from the group. We performed neurocognitive evaluations on selected children (19 of 41 children; two children were twins) born to mildly hypothyroxinemic women at full-term defined as having normal TSH and $\mathrm{FT}_{4}$ within the 0th-10th percentile interval, and who did not meet any of the exclusion criteria (22 of 41 children; Table 3 ) defined in the exclusion criteria given further on and in Table 2.

Thyroid function in all newborns was checked by the Neonatal Thyroid Screening Program, based on circulating TSH. No cases of congenital hypothyroidism were disclosed. No further measurements of thyroid function were performed in the children, although they were carefully evaluated every 3 months, until the 18th month of age, by the pediatrician involved in this project, focusing on detection of possible signs of thyroid malfunction. None of the evaluated children showed signs of hyper- or hypothyroidism and all children who were later evaluated for their neurobehavior were breastfed for at least the first 6 months of postnatal life (Table 2).

\section{Inclusion criteria}

We included (i) pregnant women above the 20th percentile at 4-6 gestational weeks and at full-term; (ii) pregnant women with mild hypothyroxinemia as defined by $\mathrm{FT}_{4}$ levels within the 0th-10th percentile interval of the normal distribution and with normal TSH values at the end of the first trimester, and with $\mathrm{FT}_{4}$ above the 20th percentile at full-term; and (iii) pregnant women with mild hypothyroxinemia at full-term, as just defined in (ii).

\section{Exclusion criteria}

We established these criteria to obtain comparably homogeneous groups of children excluding as many adverse factors as possible (other than maternal hypothyroxinemia; Table 1) that might affect both pre- and post-natal neurobehavioral development of the child. These criteria are indicated in Table 2 and concern the medical history during gestation, at delivery, and during lactation, including nutritional habits of pregnant women and their intake of drugs, the health of children until neurocognitive evaluation, and the socio-economic environment of the family. 
Table 3. Total Number of Women Enrolled, Cases that Meet the Inclusion Criteria and that Were Excluded, and Children Evaluated

\begin{tabular}{|c|c|c|c|}
\hline & Group 1 & Group 2 & Group 3 \\
\hline $\begin{array}{l}\text { Total women enrolled at the beginning of the study (at } 4-6 \mathrm{GW} \\
\text { for group 1, at 12-14 GW for group } 2 \text {, and at full-term for group 3) }\end{array}$ & 92 & 102 & 151 \\
\hline $\begin{array}{l}\text { Total no. of women that meet the inclusion criteria } \\
\text { at the beginning of the study }\end{array}$ & 46 & 21 & 40 \\
\hline Total no. of women that meet the inclusion criteria at full term & 43 & 21 & 40 \\
\hline Total no. of women/children who meet the exclusion criteria & 20 & 7 & 19 \\
\hline $\begin{array}{l}\text { Total no. of women who passed all criteria of exclusion } \\
\text { but that did not return for evaluation of the children }\end{array}$ & 10 & 2 & 3 \\
\hline $\begin{array}{l}\text { Total children who were evaluated when they were } 18 \text { months old } \\
\text { using the Brunet-Lézine test }\end{array}$ & 13 & 12 & 19 (2 twins) \\
\hline
\end{tabular}

At delivery, each mother was interviewed by the physician, filling in a questionnaire containing some of the exclusion criteria. Women that passed these criteria at delivery were interviewed 6 months later, and again those that passed the criteria were newly interviewed the day of neurobehavioral evaluation of the child. All mothers involved in this study (who passed inclusion and exclusion criteria) were fully informed and they consented to allow their infants to take part in this study.

\section{Neurobehavioral evaluation}

The Brunet-Lézine scale, revised in 1997 (21), was used to estimate the neurobehavioral development of children at 18 months of age. The test consists of four subscales to assess gross and fine motor coordination, language skills, and socialization. The child's scores on these four subscales determined a theoretical developmental age. The developmental quotient for gross and fine motor coordination, language skills, and socialization were calculated as the ratio between the theoretical developmental and the actual age of the child. Quotients between 85 and 115 indicate that the developmental age of the child falls within the normal range. Performance on the Brunet-Lézine scales was classified according to their quotients as significantly delayed (quotient: $\leq 69$ ), mildly delayed (quotient: 70-84), normal (quotient: 85-114), and accelerated (quotient: $\geq 115$ ). For children in groups 1 and 2 , the determination of a child's performance during neurobehavioral evaluations was carried out masked in the presence of two specialists who did not have access to the medical history of the mothers. This was considered necessary because they were evaluated during the same period of time. For children of group 3, tests were not masked because they were born 8-9 months earlier than children of groups 1 and 2 .

\section{Biochemical analyses}

Iodine concentrations were determined in spot urine samples by the ammonium persulfate method (22). Serum $\mathrm{FT}_{4}$ and TSH were measured at the Hospital Marina Baixa, with an ADVIA Centaur ${ }^{\circledR}$ XP immunoassay system (Siemens Medical Solutions Diagnostics Ltd., Llamberis, UK) using chemiluminiscence immunoassay kits. These kits contained primary monoclonal anti-TSH and polyclonal anti- $\mathrm{T}_{4}$ antibodies. The sensitivity was $0.3 \mathrm{ng} / \mathrm{dL}$ for $\mathrm{FT}_{4}$ and $0.03 \mu \mathrm{IU} / \mathrm{mL}$ for TSH. The inter- and intra-assay coefficients of variation were lower than those recommended by the Spanish Scientific Society of Clinical Chemistry and Molecular Biology.

\section{Statistical analysis}

We used the SYSTAT ${ }^{\circledR}$ statistical package (SYSTAT, Inc., Evanston, IL). Group comparisons were analyzed with the Kolmogorov-Smirnov test and ANOVA using the KruskalWallis test for nonparametric distributions; levels of significance were two-tailed.

\section{Results}

\section{Epidemiological data}

The Hospital Marina Baixa has an average of 1300 births per year, $22 \%$ of them by cesarean section. Healthy neonates leave the hospital 48-72 hours after birth; $83 \%$ are breast-fed on average for 3.1 months. The age of women at full-term ranged from 16 to 44 years (mean 31.1 years) and their weight gain ranged from 6 to $39 \mathrm{~kg}$ (mean $12.5 \mathrm{~kg}$ ). We found that $88 \%$ of the women reported eating fish at least twice weekly, $76 \%$ drinking daily $0.5 \mathrm{~L}$ of milk and milk-derived products, and one was a strict vegetarian. Of the total families, $83 \%$ were urban and $21 \%$ were single parent. Only $8 \%$ of the women were aware of the importance of the iodine intake during gestation and $22 \%$ used certified iodized salt.

\section{Spot iodine screening}

Iodine concentrations $(\mu \mathrm{g} / \mathrm{L})$ of spot urine samples revealed that mean values increased in groups $2(96.7 \pm 39.9$; range: $10-220)$ and 1 (120.5 \pm 41.7 ; range: $20-285)$ with respect to group 3 (74.6 \pm 0.8 ; range: $10-285 ; p<0.001)$. In group 3 , only $4.7 \%$ had a urinary iodine $>150 \mu \mathrm{g} / \mathrm{L}$ vs. $33.3 \%$ in group 2 and $33.4 \%$ in group 1 . On average, $24.1 \%$ had a urinary iodine $<50 \mu \mathrm{g} / \mathrm{L}$ in all groups (Fig. 1A).

\section{Hormone screening before iodine supplementation}

In all groups, the percentage of hypothyroxinemic women with normal TSH was very high (on average $33.0 \%$; Fig. 1A and Table 1). On average, $7.8 \%$ of them had $\mathrm{FT}_{4}$ below the normal range. Iodine-sufficient women with $\mathrm{FT}_{4}$ levels above the 20 th percentile ranged from $50.0 \%$ in group 1 at $4-6$ gestational weeks to $39.1 \%$ in group 3 at full-term. Abnormal TSH was found in one woman of group 1, two of group 2, and five of group 3 (Table 1). 


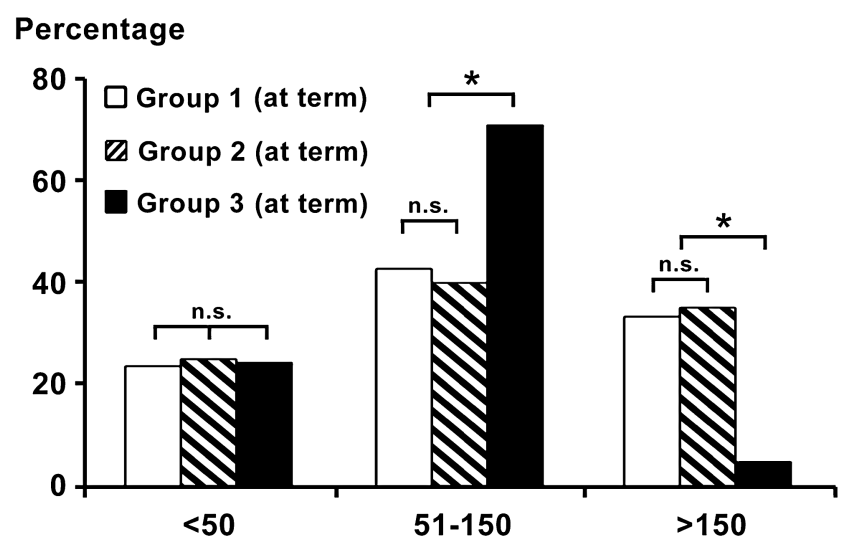

A Urinary iodine concentration ( $\mu \mathrm{g} / \mathrm{L})$
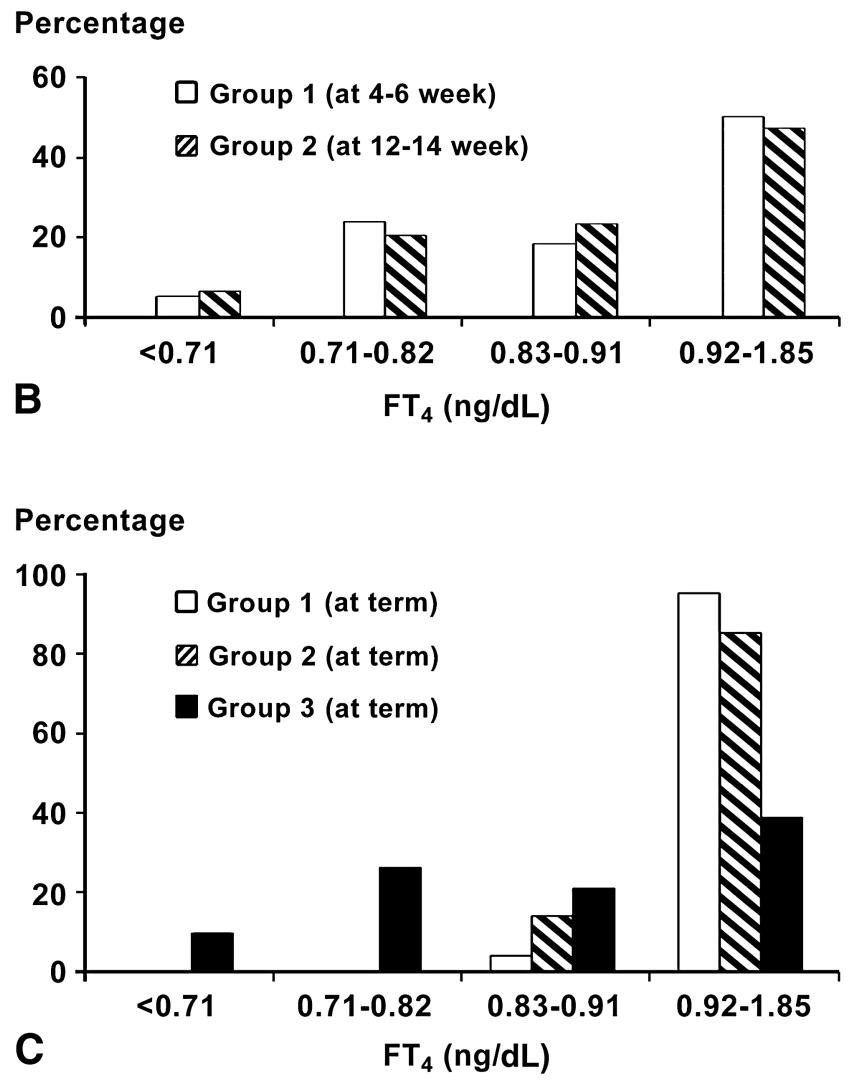

FIG. 1. (A) Frequencies of urinary iodine concentrations grouped in three intervals: below $50 \mu \mathrm{g} / \mathrm{L}$, within $51-$ $150 \mu \mathrm{g} / \mathrm{L}$, and above $150 \mu \mathrm{g} / \mathrm{L}$. The percentage of women with urinary iodine above $150 \mu \mathrm{g} / \mathrm{L}$ is lower in group 3 compared to groups 1 and 2. Frequencies of free thyroxine $\left(\mathrm{FT}_{4}\right)$ in $\mathrm{ng} / \mathrm{dL}$ are grouped in four different intervals: below the normal range $(<0.71 \mathrm{ng} / \mathrm{dL})$; within the 0th-10th percentile interval $(0.71-0.82 \mathrm{ng} / \mathrm{dL})$; within the 10th-20th percentile interval $(0.83-0.91 \mathrm{ng} / \mathrm{dL})$; and above the 20th percentile (0.92-1.85 ng/dL). (B) Serum $\mathrm{FT}_{4}$ frequencies at 46 weeks (group 1) and at 12-14 weeks of gestation (group 2). (C) $\mathrm{FT}_{4}$ frequencies found at term. Note that in group 3 the hormone determination was only performed at term. No cases in groups 1 and 2 below the normal range $(<0.71 \mathrm{ng} / \mathrm{dL})$ or within the $0.71-0.82 \mathrm{ng} / \mathrm{dL}$ interval were found at term. ${ }^{*} p<0.001$; n.s., no statistically significant differences.
Table 4. Free Thyroxine and Thyrotropin $($ MeAN \pm SD), AT TERM, OF MOTHERS of Neurocognitive-Evaluated Children

\begin{tabular}{lcc}
\hline & $F T_{4}(n g / d L)$ & $T S H(\mu I U / m L)$ \\
\hline Group 1 & $1.03 \pm 0.10(0.93-1.20)$ & $2.10 \pm 0.39(1.09-2.60)$ \\
Group 2 & $1.02 \pm 0.11(0.92-1.35)$ & $2.28 \pm 0.89(1.02-3.39)$ \\
Group 3 & $0.77 \pm 0.04(0.71-0.82)$ & $2.13 \pm 1.01(0.57-3.96)$ \\
\hline
\end{tabular}

The ranges of values are shown within brackets. Statistically nonsignificant differences were found in $\mathrm{FT}_{4}$ and $\mathrm{TSH}$ between groups 1 and 2 .

\section{Effects of iodine supplementation}

All supplemented women had normal $\mathrm{FT}_{4}$ above the 10th percentile and normal TSH (Fig. 1C and Table 1). In group 1, $4.4 \%$ had $\mathrm{FT}_{4}$ within the 10th-20th percentile interval, whereas in $95.6 \%$ it was higher. These values were also high in group $2(14.3 \%$ and $85.7 \%$, respectively) and clearly lower in group 3 ( $21.2 \%$ and $39.1 \%$, respectively). The mean $\mathrm{FT}_{4}$ values $(\mathrm{ng} / \mathrm{dL})$ increased in mothers of neurobehavioral evaluated children in group 1 and 2 to $1.03 \pm 0.10$ and $1.02 \pm 0.11$ respectively, as compared to the values of mothers in group 3 , $0.77 \pm 0.04(p<0.001 ;$ Table 4$)$.

\section{Neurocognitive development}

Due to the strict exclusion criteria (Table 2), 13 children in group $1(14.1 \%), 12$ in group $2(11.8 \%)$, and 19 children in group 3 (11.9\%; two children were twins) were included for neurobehavioral evaluation. The mean developmental quotient in group $1(101.8 \pm 9.7)$ was significantly higher than in groups $3(87.5 \pm 8.9 ; p<0.001)$ and $2(92.2 \pm 15.4 ; p<0.05)$ (Fig. 2A). Differences between groups 2 and 3 were not statistically significant $(p=0.49)$. Accelerated performance was only found in groups 1 and 2 . In group 1, 15.4\% of children showed accelerated performance vs. $8.3 \%$ in group 2 . Normal performance also increased in group $1(84.6 \%)$ with respect to groups $2(66.7 \%)$ and $3(63.2 \%$; Fig. 2B). Children with delayed performance were only observed in groups $2(25 \%)$ and 3 $(36.8 \%)$. These differences were also found when comparing quotients in each one of the four scales of the Brunet-Lézine test. Statistically significant differences $(p<0.001)$ were found in gross and fine motor coordination and socialization scales, with group 1 children obtaining the highest quotients (Fig. $2 \mathrm{C}$ ). Mean language quotients were not statistically different between groups $(p=0.45)$.

\section{Discussion}

Our results show that a delay in maternal iodine supplementation at the beginning of gestation increases the risk of neurocognitive developmental delay of their offspring. Despite the relatively small number of children evaluated in this study, the developmental differences in those with late supplementation were clearly significant. Also of note is the finding that one third $(33.0 \%)$ of the total group of pregnant women $(n=345)$ included in this study had hypothyroxinemia at full-term or earlier in gestation with normal TSH, indicating the high prevalence of dietary iodine deficiency among women of reproductive age in this coastal region of Spain. Children of mothers who suffered mild hypothyroxinemia during the first 12-14 gestational weeks (group 2) 


\section{Developmental quotient (DQ)}

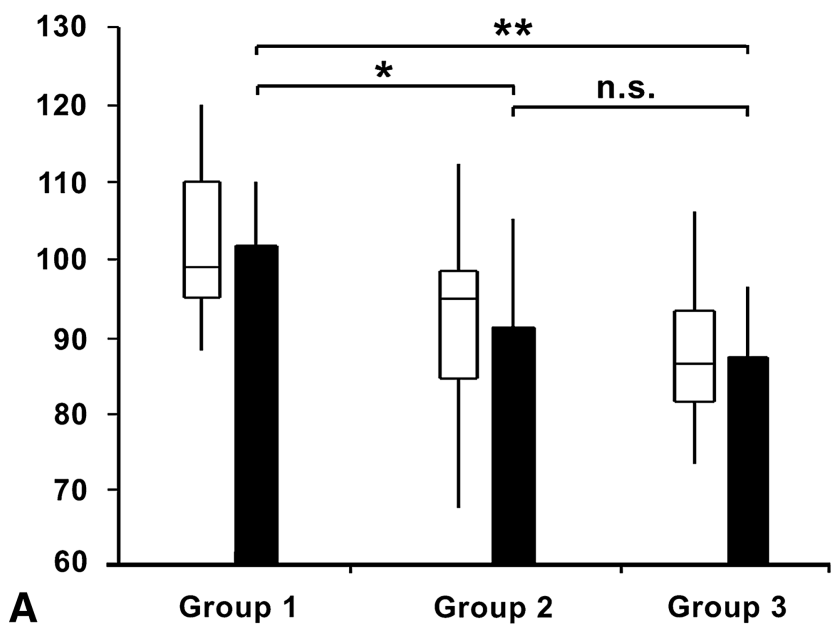

Performance (\%)

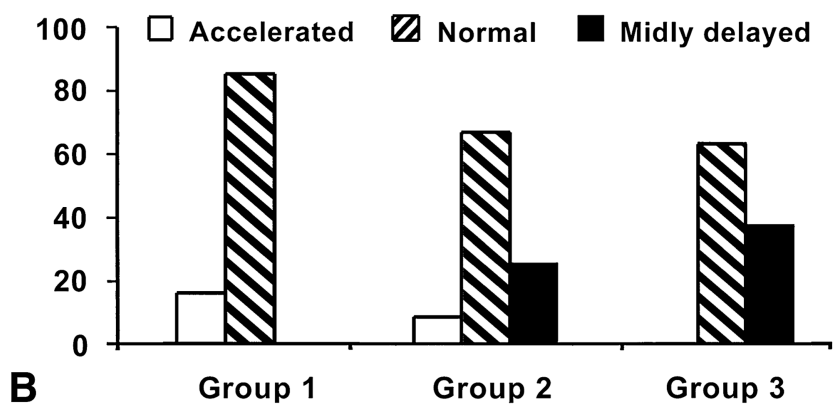

Quotient

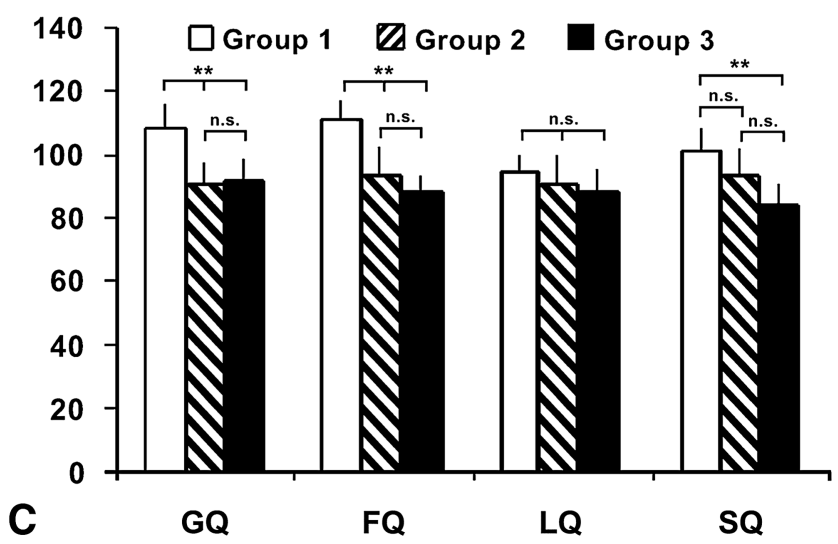

FIG. 2. (A) Mean Brunet-Lézine developmental quotients (black bars; SD in vertical lines) of children from groups 1, 2, and 3. No statistically significant differences were found between groups 2 and 3. Boxes on the left indicate the median and interquartile ranges of the data distribution. (B) The percentage of children with accelerated and normal performances increases in group 2 but remains below the group 1 values. (C) Statistically significant differences between groups were found in gross (GQ) and fine (FQ) motor coordination, and socialization (SQ) quotients. Differences between groups 1 and 2 were found in GQ and FQ scales. No difference between groups in language quotient (LQ) was found. ${ }^{*} p<0.05 ;{ }^{* *} p<0.001$; n.s., no statistically significant differences. showed lower performances in gross and fine motor coordination and socialization than those born to iodine-sufficient women with $\mathrm{FT}_{4}$ above the 20th percentile at 4-6 gestational weeks and at full-term (group 1). Performance in these three categories decreased further in children of group 3 women who were not supplemented with iodine during gestation. Iodine supplementation did not cause thyroid function alterations in pregnant women: none of groups 1 and 2 women receiving iodine supplementation were found to be hypothyroxinemic at full-term and none had abnormal $\mathrm{FT}_{4}$ or TSH.

This study has some unavoidable limitations. The number of mothers and children that passed all the inclusion and exclusion criteria was very low. Owing the low number of deliveries in the Hospital Marina Baixa (on average 1300 births per year), only 345 women could be enrolled when the study was started and 46 women (13.3\% of cases) passed the inclusion and exclusion criteria. The number of enrolled mothers per group could have been increased by keeping pregnant women without iodine supplementation but that would not have been ethically acceptable. Likewise, the number of children per group was low due to our strict exclusion criteria, which were established in order to obtain groups of children growing in comparable social environments. Another limiting factor was the determination of the thyroid function in pregnant women and in their children. Concentrations of iodine in spot urine samples are adequate for epidemiological assessments of the iodine intake of populations, but not for that of an individual, as it varies considerably within a day and from day to day. Circulating thyroid hormone determinations are a more accurate procedure to assess thyroid function, and were performed in all women at enrollment and at full-term, assuming that thyroid function was maintained within the obtained values during this period. Confirmation of this assumption by increasing the number of blood samples obtained between enrollment and full-term (a procedure not covered by our Public Health protocols) might have decreased the number of participating women and, as a consequence, that of the children returning for neurobehavioral evaluation. Thyroid function of the children was evaluated at birth by the Neonatal Thyroid Screening Program, based on circulating TSH, no further measurements being made, for the same reason just indicated for the mothers.

Epidemiological studies performed in the Netherlands (12-14), United States (15), and Russia (23) have shown neurological alterations in children from mildly to moderately hypothyroxinemic mothers. Furthermore, a prospective study from Italy reported a positive correlation between iodine deficiency during the first half of gestation and the IQ score of their children (16). In addition, $68.7 \%$ presented attention deficit hyperactivity disorder. In these studies, no signs of clinical or subclinical hypothyroidism were observed in the hypothyroxinemic mothers and their children were euthyroid at birth. In agreement with the above studies, we observed that children from groups 2 and 3 showed a significant delay in neurobehavioral development compared to those of group 1.

Using iodized salt and eating seafood 2-3 days per week, a woman's daily iodine intake would be in the order of $100-150 \mu \mathrm{g}$ per day, approximately half the amount recently recommended during pregnancy and lactation $(24,25)$. Supplementation with $200 \mu \mathrm{g}$ KI per day during pregnancy and 
lactation does not block the developing thyroid gland of the fetus and neonate $(3,4)$. In contrast, iodine supplementation from conception will ensure adequate maternal $\mathrm{FT}_{4}$ during all of gestation and lactation; especially up to midgestation, when the fetal brain is particularly vulnerable to iodine deficiency (3).

Iodized salt consumption, promoted for years in areas that are now classified as free of iodine deficiency may not be sufficient for pregnant women. In Teheran and Ilan (Islamic Republic of Iran, which was declared free of iodine deficiency by the World Health Organization in 2002), as many as $28 \%$ of pregnant women had urinary iodine concentrations below the value $(150 \mu \mathrm{g} / \mathrm{L})$ that corresponds to the minimum accepted iodine intake of $250 \mu \mathrm{g}$ per day (26). Similar findings were reported from several European countries. In Poland, where iodization of household salt became obligatory in 1997, only $37 \%$ of the pregnant women had urinary iodine concentrations above $150 \mu \mathrm{g} / \mathrm{L}$ (27). Both a study performed in Boston, where $9 \%$ of pregnant women had urinary iodine concentrations below $50 \mu \mathrm{g} / \mathrm{L}(28)$, and a report of the National Health and Nutrition Examination Surveys (NHANES III) (29) have pointed out that urinary iodine is well below the values recommended by the World Health Organization and the International Council for Control of Iodine Deficiency Disorders (28-30). To prevent iodine deficiency, the American Thyroid Association (31) promoted iodine supplementation for pregnancy and lactation in the United States and Canada, recommending supplements of $150 \mu \mathrm{g}$ iodine per day, this being the maximum permitted in nutritional supplements for pregnancy dispensed over-the-counter. Our present data reveal that this recommendation cannot cover the iodine requirements of all pregnant women in mildly to moderately iodine-deficient countries such as Spain and the United States, among others (31). In fact, after $200 \mu \mathrm{g}$ KI per day supplementation from 12 to 14 gestational weeks until end of lactation to women in group 2, and from 4 to 6 gestational weeks to women in group 1, urinary iodine increased in women of these groups but still remained below the minimal values $(150 \mu \mathrm{g} / \mathrm{L})$ recommended by the World Health Organization $(3,4)$ : urinary iodine was on average $103.7 \mu \mathrm{g} / \mathrm{L}$, with only $33.4 \%$ having more than $150 \mu \mathrm{g} / \mathrm{L}$ and $23.8 \%$ having less than $50 \mu \mathrm{g} / \mathrm{L}$. It would be very interesting to establish an individual subject correlation between urinary iodine and offspring neurocognitive performance. However, it was not possible since urinary iodine was determined at full-term from spot samples. As already indicated above, the values obtained in spot urine samples are appropriate for epidemiological surveys of populations, but are inadequate for assessment of the iodine availability of individual members (32). In addition to a delay in iodine supplementation, differences in the degree and/or duration of iodine deficiency during gestation might also play a role. The high proportion of hypothyroxinemic women found in this study $(33.0 \%)$ reveals that normal iodine intake has not been achieved and still remains a primary public health problem even in developed countries. Similar percentages of hypothyroxinemic pregnant women, or even greater (up to $50 \%$ ), have been found in countries supposed to be iodine sufficient such as the United Kingdom (33).

The present results indicate a delay in neurocognitive development of 18-month-old children from mildly hypothyroxinemic women who received delayed iodine supplementation and are at risk of suffering permanent neurological alter- ations. Although some of them might overcome delayed neurobehavioral development when growing in an enriched environment, the risk exists of suffering permanent neurological alterations. In fact, altered migration in the cerebral cortex was found in rats and mice that suffered mild and transient hypothyroxinemia for only 3 days at the beginning of corticogenesis $(18,20)$. This period of time might correspond in humans to about 6 weeks of gestation, roughly from embryonic day 46 until the end of the first trimester. In addition, $\mathrm{T}_{4}$ treatment of the rodents soon after inducing maternal hypothyroxinemia prevented the neurodevelopmental damage. When treatment was delayed, the alterations persisted (19).

Prospective studies on autism disorders $(34,35)$ have found that children diagnosed at 8-18 years of age had a more retarded social development when they where 18 months old than nonautistic ones (35). We have found that five children in group 3 had a delayed development quotient, with socialization quotients more than 15 points below the fine motor quotients, suggesting that they are at risk for developing disorders of the autism spectrum. The hypothesis that these children are at risk for developing disorders of the autism spectrum is not unlikely. In fact, a recent study points out that anti-thyroid environmental substances and pollutants can affect the thyroid function during pregnancy, increasing the risk of autism in the population (36).

Differences found in gross and fine motor coordination and socialization skills, which involve neocortical areas as well as other subcortical structures as the amygdaloid complex, might indicate that early maternal hypothyroxinemia might have affected maturation and/or cortical connectivity, as occurs in animal models (18-20). In humans, these alterations might be also present in those neocortical areas, other than Broca's and Wernicke's, involved in language such as auditory, visual, somatosensory, and motor areas. However, no differences on language performance were found between groups, which may reflect a deficient discrimination capacity of the test in language performance in 18-month-old children. Thus, language and other complex behaviors whose neural substrates need thyroid hormone postnatally for a normal development should be tested later, when these cortical areas are in a more advanced stage of development.

In conclusion, implementation of universal salt iodization and provision of iodine supplements during pregnancy and lactation are intended to ensure that children reach their full potential development, avoiding the tragedy of a mental retardation caused by a preventable micronutrient deficiency. We have found that a delay of 6-10 weeks in iodine supplementation of pregnant women at the beginning of gestation in an area of mild iodine deficiency increases the risk of their offspring suffering permanent alterations in gross and fine motor coordination and social development. Therefore, we strongly support for this region the recommendation of a daily $200 \mu \mathrm{g}$ iodine supplement to all women considering conception, during pregnancy, and throughout lactation $(3,4)$, without wasting critical weeks for confirmation that iodine intake is inadequate. Just as folates are recommended without awaiting confirmation of a possible folate deficiency, iodine supplementation likewise should not be delayed. Our data reveal that iodine supplementation is urgent and independent from possible future implementation of thyroid function screening of every woman at the beginning of pregnancy. 


\section{Acknowledgments}

We thank Profs. J. Bernal, G.C. Román, and C. Sotelo and Dr. C. Berbel for critical reading of the manuscript and those parents who agreed to allow their infants to take part in this study. The help of nursing colleagues and technicians involved at different stages of this work is deeply appreciated. Supported by a grant of the Spanish Ministerio de Educación y Ciencia (SAF2006-14068) to PB.

\section{Disclosure Statement}

No competing financial interests exist.

\section{References}

1. Morreale de Escobar G, Obregón MJ, Escobar del Rey F 2007 Iodine deficiency and brain development in the first half of pregnancy. Public Health Nutr 10:1554-1570.

2. Hetzel BS 1994 Iodine deficiency and fetal brain damage. N Engl J Med 331:1770-1771.

3. WHO Secretariat, Andersson M, de Benoist B, Delange F, Zupan J 2007 Prevention and control of iodine deficiency in pregnant and lactating women and in children less than 2-years-old: conclusions and recommendations of the Technical Consultation. Public Health Nutr 10:1606-1611.

4. Zimmermann MB 2007 Iodine requirements in pregnancy and infancy. IDD Newsletter 23(1):1-2. Available at http:// www.iccidd.org/media/IDD\%20Newsletter/2007-present/ feb2007.pdf. Accessed October 8, 2008.

5. Zoeller RT, Rovet J 2004 Timing of thyroid hormone action in the developing brain: Clinical observations and experimental findings. J Neuroendocrinol 16:809-818.

6. Morreale de Escobar G, Obregón MJ, Escobar del Rey F 2000 Is neuropsychological development related to maternal hypothyroidism, or to maternal hypothyroxinemia? J Clin Endocrinol Metab 85:3975-3987.

7. Morreale de Escobar G, Obregón MJ, Escobar del Rey F 2004 Role of thyroid hormone during early brain development. Eur J Endocrinol 151:25-37.

8. Marín-Padilla M 1990 Origin, formation and prenatal maturation of the human cerebral cortex: an overview. J Craniofac Gen Dev Biol 10:137-146.

9. Bernal J, Pekonen F 1984 Ontogenesis of the nuclear 3,5,3'thriiodothyronine receptor in the human fetal brain. Endocrinology 114:677-679.

10. Chan S, Kilby MD 2000 Thyroid hormone and central nervous system development. J Endocrinol 165:1-8.

11. Davis PJ, Davis FB, Cody V 2005 Membrane receptors mediating thyroid hormone action. Trends Endocrinol Metab 16:429-435.

12. Pop VJ, Kuijpens JL, van Baar AL, Verkerk G, van Son MM, de Vijlder JJ, Vulsma T, Wiersinga WM, Drexhage HA, Vader HL 1999 Low maternal free T4 concentrations during early pregnancy are associated with impaired psychomotor development in infancy. Clin Endocrinol (Oxf) 50: 149-155.

13. Pop VJ, Brouwers EP, Vader HL, Vulsma T, van Baar AL, de Vijlder JJ 2003 Maternal hypothyroxinemia during early pregnancy and subsequent child development: a 3-year follow-up study. Clin Endocrinol (Oxf) 59:282-288.

14. Kooistra L, Crawford S, van Baar AL, Brouwers EP, Pop VJ 2006 Neonatal effects of maternal hypothyroxinemia during early pregnancy. Pediatrics 117:161-167.
15. Haddow JE, Palomaki GE, Allan WC, Williams JR, Knight GJ, Gagnon J, O'Heir CE, Mitchell ML, Hermos RJ, Waisbren SE, Faix JD, Klein RZ 1999 Maternal thyroid deficiency during pregnancy and subsequent neuropsychological development of the child. $N$ Engl J Med 341: 549-555.

16. Vermiglio F, Lo Presti VP, Moleti M, Sidoti M, Tortorella G, Scaffidi G, Castagna MG, Mattina F, Violi MA, Crisà A, Artemisia A, Trimarchi F 2004 Attention deficit and hyperactivity disorders in the offspring of mothers exposed to mild-moderate iodine deficiency: a possible novel iodine deficiency disorder in developed countries. J Clin Endocrinol Metab 89:6054-6060.

17. Berbel P, Obregón MJ, Bernal J, Escobar del Rey F, Morreale de Escobar G 2007 Iodine supplementation during pregnancy: a public health challenge. Trends Endocrinol Metab 18:338-343.

18. Lavado-Autric R, Ausó E, García-Velasco JV, Arufe Mdel C, Escobar del Rey F, Berbel P, Morreale de Escobar G 2003 Early maternal hypothyroxinemia alters histogenesis and cerebral cortex cytoarchitecture of the progeny. J Clin Invest 111:1073-1082.

19. Ausó E, Lavado-Autric R, Cuevas E, Escobar del Rey F, Morreale de Escobar G, Berbel P 2004 A moderate and transient deficiency of maternal thyroid function at the beginning of fetal neocorticogenesis alters neuronal migration. Endocrinology 145:4037-4047.

20. Cuevas E, Ausó E, Telefont M, Morreale de Escobar G, Sotelo C, Berbel P 2005 Transient maternal hypothyroxinemia at onset of corticogenesis alters tangential migration of MGE-derived neurons. Eur J Neurosci 22: 541-551.

21. Josse D 1997 Brunet-Lézine revise: Échelle de développement psychomoteur de la première infance. Établissement d'Applications Psychotecniques, Paris.

22. Pino S, Fang SL, Braverman LE 1996 Ammonium persulfate: a safe alternative oxidizing reagent for measuring urinary iodine. Clin Chem 42:239-243.

23. Kasatkina EP, Samsonova LN, Ivakhnenko VN, Ibragimova GV, Ryabykh AV, Naumenko LL, Evdokimova YA 2006 Gestational hypothyroxinemia and cognitive function in offspring. Neurosci Behav Physiol 36:619-624.

24. Glinoer D 2007 The importance of iodine nutrition during pregnancy. Public Health Nutr 10:1542-1546

25. Kester MH, Martinez de Mena R, Obregon MJ, Marinkovic D, Howatson A, Visser TJ, Hume R, Morreale de Escobar G 2004 Iodothyronine levels in the human developing brain: Major regulatory roles of iodothyronine deiodinases in different areas. J Clin Endocrinol Metab 89:3117-3128.

26. Azizi F, Aminorroya A, Hedayati M, Rezvanian H, Amini M, Mirmiran P 2003 Urinary iodine excretion in pregnant women residing in areas with adequate iodine intake. Public Health Nutr 6:95-98.

27. Szybinski Z 2005 Iodine deficiency in pregnancy: a continuing public health problem. Endokrynol Pol 56:65-71.

28. Pearce EN, Bazrafshan HR, He X, Pino S, Braverman LE 2004 Dietary iodine in pregnant women from the Boston, Massachusetts area. Thyroid 14:327-328.

29. Hollowell JG, Staehling NW, Hannon WH, Flanders DW, Gunter EW, Maberly GF, Braverman LE, Pino S, Miller DT, Garbe PL, DeLozier DM, Jackson RJ 1998 Iodine nutrition in the United States. Trends and public health implications: 
iodine excretion data from National Health and Nutrition Examination Surveys I and III (1971-1974 and 1988-1994). J Clin Endocrinol Metab 83:3401-3408.

30. Haddow JE, McClain MR, Palomaki GE, Hollowell JG 2007 Urine iodine measurements, creatinine adjustment, and thyroid deficiency in an adult United States population. J Clin Endocrinol Metab 92:1019-1022.

31. Utiger RD 2006 Iodine nutrition-more is better. N Engl J Med 354:2819-2821.

32. Zimmermann MB, Jooste PL, Pandav CS 2008 Iodinedeficiency disorders. Lancet 372:1251-1262.

33. Lazarus JH, Smyth PP 2008 Iodine deficiency in the UK and Ireland. Lancet 372:888.

34. Peterson CC, Slaughter VP, Paynter J 2007 Social maturity and theory of mind in typically developing children and those on the autism spectrum. J Child Psychol Psychiatry 48:1243-1250.
35. Johnson MH, Siddons F, Frith U, Morton J 1992 Can autism be predicted on the basis of infant screening tests? Dev Med Child Neurol 34:316-320.

36. Román G 2007 Autism: transient in utero hypothyroxinemia related to maternal flavonoid ingestion during pregnancy and to other environmental antithyroid agents. J Neurol Sci 262:15-26.

Address reprint requests to: Pere Berbel, Ph.D. Instituto de Neurociencias de Alicante Universidad Miguel Hernández and CSIC Apdo. de Correos 18, Sant Joan d'Alacant 03550 Alicante Spain

E-mail: pere.berbel@umh.es 
